\title{
Does Consumption of Coloring Substances during Tooth Whitening Treatment Influence the Final Outcome? A Systematic Review
}

O Consumo de Corantes durante o Clareamento Dental Influência no Resultado Final? Uma Revisão Sistemática ¿Influye el Consumo de Colorantes durante el Tratamiento de Blanqueamiento Dental en el Resultado Final? Una Revisión Sistemática

Marilia de Lima SOARES

Adjunt Professor, DDS, PhD. Dentistry School, UNIFBV - University Center of Boa Viagem, Recife, Pernambuco, Brazil https://orcid.org/0000-0002-6755-2649

Marianne de Vasconcelos CARVALHO

Adjunct Professor, DDS, PhD. Dentistry School, UPE - University of Pernambuco, Camaragibe, Pernambuco, Brazil https://orcid.org/0000-0002-6815-5696 Cleidiel Aparecido Araújo LEMOS Adjunct Professor, DDS, PhD. Dentistry School, UFJF - Federal University of Juiz de Fora, Governador Valadares, Minas Gerais, Brazil https://orcid.org/0000-0001-8273-489X

Juliana Raposo SOUTO MAIOR

Adjunct Professor, DDS, PhD. Dentistry School, UFPE - Federal University of Pernambuco, Recife, Pernambuco, Brazil https://orcid.org/0000-0003-0277-6171 Sandra Lúcia Dantas de MORAES

Adjunct Professor, DDS, PhD. Dentistry School, UPE - University of Pernambuco, Camaragibe, Pernambuco, Brazil https://orcid.org/0000-0002-3154-5092

Belmiro Cavalcanti do Egito VASCONCELOS Senior Lecturer in Oral and Maxillofacial Surgery, DDs, PhD, Director of Master's and PhD Programs in Oral and Maxillofacial Surgery, Dentistry School, UPE - University of Pernambuco, Camaragibe, Pernambuco, Brazil https://orcid.org/0000-0002-6515-1489 Cleber Davi Del Rei Daltro RosA

MSc student. Department of Dental Materials and Prosthodontics, Dentistry School, UNESP - São Paulo State University, Araçatuba, São Paulo, Brazil https://orcid.org/0000-0002-7350-2525 Eduardo Piza PELLIZZER Full Professor, DDS, PhD. Department of Dental Materials and Prosthodontics, Dentistry School, UNESP - São Paulo State University, Araçatuba, São Paulo, Brazil

https://orcid.org/0000-0003-0670-5004

\section{Abstract}

\begin{abstract}
The purpose of this systematic review recorded in PROSPERO (CRD4201913125) was to test the hypothesis that dye substances during and / or immediately after treatment can affect the effectiveness of tooth whitening. Two independent reviewers performed a search was conducted in the PubMed / MEDLINE, Web of Science databases and Cochrane Library. Articles were selected based on the inclusion criteria: in vitro studies with direct comparisons between groups undergoing treatment with or without dying substances consumption during or immediately after bleaching treatment; reflectance spectrophotometry was used as evaluation method; studies in which any type of dye was used, studies in which treatment was performed on human and / or bovine teeth. Of the 8 studies selected, including 347 samples analyzed in vitro. The coffee does not appear to influence tooth whitening when consumed during tooth whitening sessions or immediately after treatment (up to 24 hours after treatment). However low-alcoholic beverages such as red wine and cola drinks may have the potential to change pigmentation and influence the change in tooth color.
\end{abstract}

Descriptors: Tooth Bleaching; Coloring Agents; Systematic Review.

\section{Resumo}

O objetivo desta revisão sistemática registrada no PROSPERO (CRD4201913125) foi testar a hipótese de que o uso das substâncias corante durante e / ou imediatamente após o tratamento podem afetar a eficácia do clareamento dental. Dois revisores independentes realizaram uma pesquisa nas bases de dados PubMed / MEDLINE, Web of Science e Cochrane Library. Os artigos foram selecionados com base nos critérios de inclusão: estudos in vitro com comparações diretas entre grupos em tratamento com ou sem consumo de corantes durante ou imediatamente após o tratamento clareador; a espectrofotometria de refletância foi utilizada como método de avaliação; estudos em que foi utilizado qualquer tipo de corante; estudos em que o tratamento foi realizado em dentes humanos e / ou bovinos. Oito estudos selecionados, incluindo 347 amostras analisadas in vitro. $O$ café não parece influenciar o clareamento dental quando consumido durante as sessões de clareamento dental ou imediatamente após o tratamento (até 24 horas após o tratamento). No entanto, bebidas com baixo teor de álcool, como vinho tinto, refrigerantes, podem ter o potencial de alterar a pigmentação e influenciar a mudança na cor dos dentes.

Descritores: Tooth Bleaching; Coloring Agents; Systematic Review.

\section{Resumen}

El objetivo de esta revisión sistemática registrada en PROSPERO (CRD4201913125) fue probar la hipótesis de que el uso de colorantes durante y / o inmediatamente después del tratamiento puede afectar la efectividad del blanqueamiento dental. Dos revisores independientes realizaron una búsqueda en las bases de datos PubMed / MEDLINE, Web of Science y Cochrane Library. Los artículos fueron seleccionados en base a los criterios de inclusión: estudios in vitro con comparaciones directas entre los grupos en tratamiento con o sin consumo de colorantes durante o inmediatamente después del tratamiento de blanqueamiento; se utilizó espectrofotometría de reflectancia como método de evaluación; estudios en los que se utilizó cualquier tipo de tinte; estudios en los que se realizó tratamiento en dientes humanos y / o bovinos. Ocho estudios seleccionados, incluidas 347 muestras analizadas in vitro. El café no parece influir en el blanqueamiento dental cuando se consume durante las sesiones de blanqueamiento dental o inmediatamente después del tratamiento (hasta 24 horas después del tratamiento). Sin embargo, las bebidas con bajo contenido de alcohol, como el vino tinto y los refrescos, pueden tener el potencial de alterar la pigmentación e influir en el cambio de color de los dientes.

Descriptores: Blanqueamiento de Dientes; Colorantes; Revisión Sistemática.

\section{INTRODUCTION}

Several factors can alter the esthetics of a smile, including changes in the teeth coloring ${ }^{1}$. Dental whitening is a conservative and safe procedure which involves the use of hydrogen peroxide or carbamide peroxide in various concentrations and times of application with or without light ${ }^{2}$. These bleaching gels are unstable and, when in contact with oral fluid, releases oxygen and free radicals that break down pigment macromolecules via oxidation and reducing its concentration, thereby whitening the teeth $^{3}$. When in contact with bleaching gels, the enamel undergo temporary structural alterations, 
such as reduction in microhardness, increase in surface roughness, porosity and demineralization ${ }^{4-7}$.

Some colored drinks and foods, such as red wine, coffee, cola soft drinks, chocolates, among others, produce a greater influence on teeth staining. However, the consumption of such beverages and foods is highly popular worldwide $^{8}$. Due to the possibility of these products influencing on the final effect and color stability obtained by bleaching, professionals advise patients to avoid the intake of food and drink with colorants during and after treatment ${ }^{1}$. Notably, during and/or after tooth whitening procedures, a permanent total ban of these drinks and foods for aesthetic purposes is impractical for most people ${ }^{8}$.

The consumption of dying substances after tooth whitening is well established as a cause of loss of color stabilization and dimming ${ }^{9}$, however there is a general lack of information regarding the esthetic damage caused by dyes during or shortly after the bleaching treatment in relation to the final outcome.

Therefore, the overall goal of this systematic review was to test the hypothesis that coloring substances used during and/or immediately after treatment affect the effectiveness of tooth whitening.

MATERIAL AND METHOD

The present systematic review was performed following the recommendations of the Preferred Reporting Items for Systematic Reviews and Meta-Analyses statement [10]. Furthermore, the systematic review was registered in PROSPERO (CDR42019131255).

- Eligibility criteria

The question of this systematic review was as follows: Does the consumption of coloring substances during dental bleaching influence the efficacy of the treatment? The studies selected for this review met the criteria established by the PICO (population, intervention, control, and outcomes) approach. Population: Teeth who underwent dental bleaching; Intervention: Teeth subjected to coloring substances during the bleaching treatment; Comparison: Teeth no subjected to coloring substances during the bleaching treatment; Outcome: Effectiveness of tooth whitening.

Eligible articles were published until november 2019, published in English, in vitro studies with direct comparisons between groups that underwent treatment with or without consumption of coloring substances during or immediately after bleaching treatment (up to $24 \mathrm{~h}$ after treatment); studies in which reflectance spectrophotometry was used as evaluation method; studies in which any type of coloring substance was used; studies in which the treatment was performed on human and/or bovine teeth. Case reports, reviews and articles that did not report relevant data for the purpose of this study were excluded.

\section{- Information Source and Search Strategy}

A comprehensive search of studies published and listed in the PubMed/MEDLINE, Web of Science, Scopus and Cochrane Library databases (until $30^{\text {st }}$ November 2019) was performed using a combination of the following search terms: ((("dental health services"[MeSH Terms] OR ("dental"[All Fields] AND "health"[All Fields] AND "services"[All Fields]) OR "dental health services"[All Fields] OR "dental"[All Fields]) AND bleaching[All Fields]) OR (("dental health services"[MeSH Terms] OR ("dental"[All Fields] AND "health"[All Fields] AND "services"[All Fields]) OR "dental health services"[All Fields] OR "dental"[All Fields]) AND whitening[All Fields])) AND (("coffee"[MeSH Terms] OR "coffee"[All Fields]) OR ("wine"[MeSH Terms] OR "wine"[All Fields]) OR ("tea"[MeSH Terms] OR "tea"[All Fields]) OR juice[All Fields] OR ("fruit"[MeSH Terms] OR "fruit"[All Fields]) OR ("diet"[MeSH Terms] OR "diet"[All Fields]) OR ("pigmentation"[MeSH Terms] OR "pigmentation"[All Fields] OR "pigments"[All Fields]) OR (("staining and labeling"[MeSH Terms] OR ("staining"[All Fields] AND "labeling"[All Fields]) OR "staining and labeling"[All Fields] OR "staining"[All Fields]) AND ("beverages"[MeSH Terms] OR "beverages"[All Fields])) OR ("coloring agents"[Pharmacological Action] OR "coloring agents"[MeSH Terms] OR ("coloring"[All Fields] AND "agents"[All Fields]) OR "coloring agents"[All Fields] OR "dye"[All Fields])). The articles were selected individually by two of the authors (M.L.S. and C.A.A.L.). All authors analyzed the differences in choices between M.L.S. and C.A.A.L. and consensus was reached by discussion. The same authors performed a manual search of studies in the reference list of the articles identified in the databases. Also, manual searches of three highimpact dentistry journals comprising the last 6 months were performed: American Journal of Dentistry, International Journal of Dentistry and Brazilian Dental Journal.

\section{- Quality Assessment of Selected Studies}

The studies were analyzed to identify the risk of bias in the results and conclusions. The modified Methodological Index for NonRandomized Studies (MINORS) was used for this evaluation for the in vitro ${ }^{11}$. The "Inclusion 
of consecutive patients" (item 2 of the MINORS scale) was replaced for "Inclusion of confection methods of the specimens".

Twelve items were evaluated, and each item was scored from 0 to 2, where 0 indicates that the item was not reported in the assessed article; 1 indicates that the item was reported, but inadequately; and 2 indicates that the item was reported adequately. Studies with a score above 16 were considered as having a low risk of bias and those with a score below 16 were considered high risk.

\section{- Data collection}

Data were extracted from the selected articles by one of the authors (M.L.S.). The extracted data were sorted as quantitative or qualitative, tabulated for ease of comparison, and verified by all researchers. Table 1 presents data from the in vitro studies. Any disagreements were solved through discussion until a consensus was obtained. The following data were identified in each article: author/date, study design, coloring substances, sample size, groups, bleaching agents, evaluation methods, evaluation time, bleaching efficacy, and treatment outcome.

\section{- Additional Analysis}

The articles were selected by the authors (M.L.S. and C.A.A.L.) and the kappa score was used to calculate the inter-rater agreement during the inclusion process of publications databases $^{12}$. Agreement was reached by consensus, with differences being discussed and resolved by all authors.

\section{RESULTS}

- Selection of the studies and risk of bias

The initial search of the databases identified 688 articles, including 296 in PubMed/MEDLINE, 77 in Web of Science, 253 in Scopus and 62 in Cochrane Library. After reading the titles and abstracts, 8 articles were selected for full-text analysis. All 8 studies were included in this review and processed for data extraction (Table 1). All completed papers were included in the qualitative analysis in this review. The PRISMA flow diagram showing the complete selection process and inclusion of the articles is illustrated in Figure 1.

The kappa coefficient was applied to the selection of the abstracts and used to calculate the inter-rater agreement during the inclusion process of publications from the PubMed/MEDLINE (kappa $=0.75)$, Web of Science $(\mathrm{kappa}=0.86)$, Scopus $(\mathrm{kappa}=1.0)$ and Cochrane Library (kappa $=1.0$ ) databases. The kappa values indicated a high level of agreement between raters. Agreement was reached by consensus, with differences being discussed and resolved by all authors.

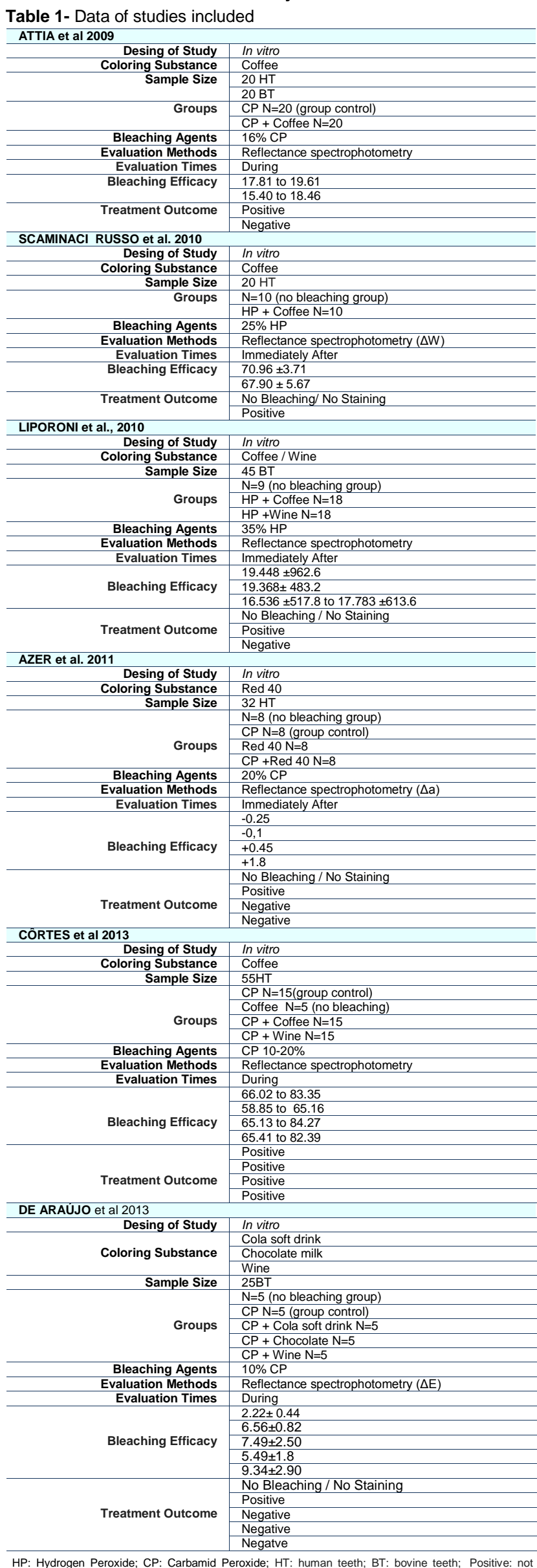

HP: Hydrogen Peroxide; CP: Carbamid Peroxide; HT: human teeth; BT: bovine teeth; Positive: not influenced the outcome, Neg. Carbamid Peroxide, HT: hum 
Table 1 (continuation) - Data of studies included

\begin{tabular}{|c|c|}
\hline PIROLO et al. 2014 & \\
\hline Desing of Study & In vitro \\
\hline Coloring Substance & $\begin{array}{l}\text { Cola soft drink } \\
\text { Coffee }\end{array}$ \\
\hline Sample Size & $60 \mathrm{BT}$ \\
\hline Groups & $\begin{array}{l}\text { HP + Cola soft drink } N=30 \\
H P+\text { Coffee } N=30\end{array}$ \\
\hline Bleaching Agents & $35 \% \mathrm{HP}$ \\
\hline Evaluation Methods & Reflectance spectrophotometry $(\Delta \mathrm{E})$ \\
\hline Evaluation Times & Immediately After \\
\hline Bleaching Efficacy & $4.11 \pm 0.64$ \\
\hline & $1.49 \pm 0.51$ \\
\hline Treatment Outcome & Negative \\
\hline & Positive \\
\hline CORREIA et al. 2017 & \\
\hline Desing of Study & In vitro \\
\hline & Distilled water \\
\hline & $\begin{array}{l}\text { Coffee } \\
\text { Cola soft drink }\end{array}$ \\
\hline Coloring Substance & Black tea \\
\hline & $\begin{array}{l}\text { Wine } \\
\text { Chocolate milk }\end{array}$ \\
\hline & Shoyo \\
\hline Sample Size & $70 \mathrm{BT}$ \\
\hline & $\begin{array}{l}\mathrm{CP} \mathrm{N}=10 \text { (group control) } \\
\mathrm{CP}+\text { Coffee } \mathrm{N}=10\end{array}$ \\
\hline & $\mathrm{CP}+$ Cola soft drink $\mathrm{N}=10$ \\
\hline Groups & $\mathrm{CP}+$ Black tea $\mathrm{N}=10$ \\
\hline & $C P+$ Wine $N=10$ \\
\hline & $\begin{array}{l}\mathrm{CP}+\text { Chocolate } \mathrm{N}=10 \\
\mathrm{CP}+\text { Shoyo } \mathrm{N}=10\end{array}$ \\
\hline Bleaching Agents & $22 \% \mathrm{CP}$ \\
\hline Evaluation Methods & Reflectance spectrophotometry $(\Delta \mathrm{E})$ \\
\hline Evaluation Times & Immediately After \\
\hline & $\frac{5.31}{6.93}$ \\
\hline & 6.40 \\
\hline Bleaching Efficacy & 4.36 \\
\hline & 4.09 \\
\hline & 4.49 \\
\hline & $\begin{array}{l}8.15 \\
\text { Positive }\end{array}$ \\
\hline & Positive \\
\hline & Positive \\
\hline Treatment Outcome & $\begin{array}{l}\text { Positive } \\
\text { Positiva }\end{array}$ \\
\hline & $\begin{array}{l}\text { Positive } \\
\text { Positive }\end{array}$ \\
\hline & $\begin{array}{l}\text { Positive } \\
\text { Negative }\end{array}$ \\
\hline
\end{tabular}

HP: Hydrogen Peroxide; CP: Carbamid Peroxide; HT: human teeth; BT: bovine teeth; Positive: not influenced the outcon

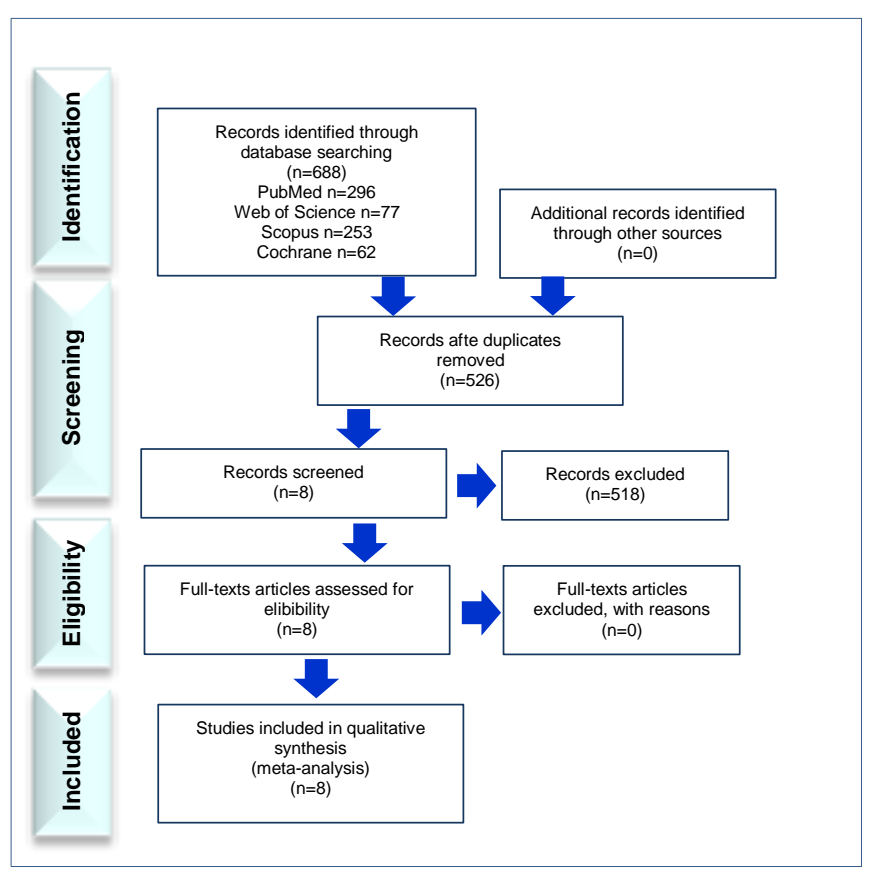

Figure 1 Search strategy

To assess the quality of all of the selected studies, the risk of bias was evaluated using the modified MINORS scale. All the studies had a score of 18; all studies were classified as having a low risk of bias (Table 2).

- Description of the Studies

A detailed description of the studies included is shown in Tables 1 . Of the 9 selected studies, it was possible to analyze 347 samples.
Among all the studies, coffee was the most frequently used coloring substance (6 studies) $)^{2,8,13-16}$, followed by red wine

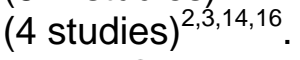

Other substances were included, such as: Coke (3 studies) ${ }^{2,3,8}$, Chocolate (2 studies) ${ }^{2,3}$, red $40\left(1\right.$ study) ${ }^{18}$, black tea (1 study) ${ }^{2}$ and shoyu sauce (1 study) ${ }^{2}$.

Table 2 - Quality assessment and risk of bias

\begin{tabular}{|c|c|}
\hline \multicolumn{2}{|l|}{ ATTIA et al 2009} \\
\hline Aim of the study & 2 \\
\hline Confection methods of the specimens & \\
\hline Collection of data & 2 \\
\hline Endpoint appropriate & 2 \\
\hline Unbiased evaluation & 0 \\
\hline Follow-up & 2 \\
\hline Loss to follow up & 0 \\
\hline Control group & 0 \\
\hline Contemporary groups & 2 \\
\hline Baseline & 2 \\
\hline Sample size & 2 \\
\hline Statistical analyzes & 2 \\
\hline Risk of bias & \\
\hline \multicolumn{2}{|l|}{ LIPORONI et al. 2010} \\
\hline Aim of the study & \\
\hline Confection methods of the specimens & 2 \\
\hline Collection of data & 2 \\
\hline Endpoint appropriate & 2 \\
\hline Unbiased evaluation & 0 \\
\hline Follow-up & \\
\hline Loss to follow up & 0 \\
\hline Control group & 0 \\
\hline Contemporary groups & 2 \\
\hline Baseline & 2 \\
\hline Sample size & \\
\hline Statistical analyzes & 2 \\
\hline Risk of bias & \\
\hline
\end{tabular}

SCAMINACI et al. 2010

Risk of bias

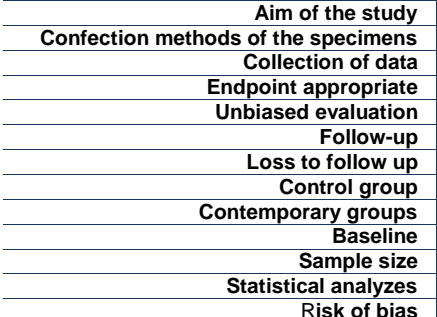

\begin{tabular}{|r|r|}
\hline \multicolumn{2}{|c}{ Risk of bias } \\
\hline AZZER et al. $2011 \quad$ Aim of the study \\
\hline
\end{tabular}

\begin{tabular}{r|l} 
Aim of the study & 2 \\
\hline Confection methods of the specimens & 2 \\
\hline Collection of data & 2 \\
\hline Endpoint appropriate & 2 \\
\hline Unbiased evaluation & 0 \\
\hline Follow-up & 2 \\
\hline Loss to follow up & 0 \\
\hline Control group & 0 \\
\hline Contemporary groups & 2 \\
Baseline & 2 \\
\hline Sample size & 2 \\
\hline Statistical analyzes & 2 \\
Risk of bias & Low
\end{tabular}

\begin{tabular}{rr|r}
\hline & Risk of bias \\
\hline CÓRTES et al. 2003 & \\
\hline & Aim of the study
\end{tabular}

\begin{tabular}{r|c} 
Aim of the study & 2 \\
\hline Confection methods of the specimens & 2 \\
Collection of data & 2 \\
\hline Endpoint appropriate & 2 \\
Unbiased evaluation & 0 \\
Follow-up & 2 \\
\hline Loss to follow up & 0 \\
\hline Control group & 0 \\
\hline Contemporary groups & 2 \\
Baseline & 2 \\
Sample size & 2 \\
\hline Statistical analyzes & 2 \\
Risk of bias & \\
\hline
\end{tabular}

DE ARAÚJO et al. 2013

Risk of bias

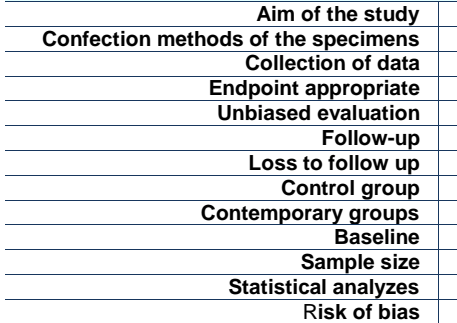

\begin{tabular}{|l}
\hline 2 \\
2 \\
\hline 2 \\
2 \\
0 \\
2 \\
0 \\
0 \\
\hline 2 \\
\hline 2 \\
\hline 2 \\
2 \\
Low
\end{tabular}




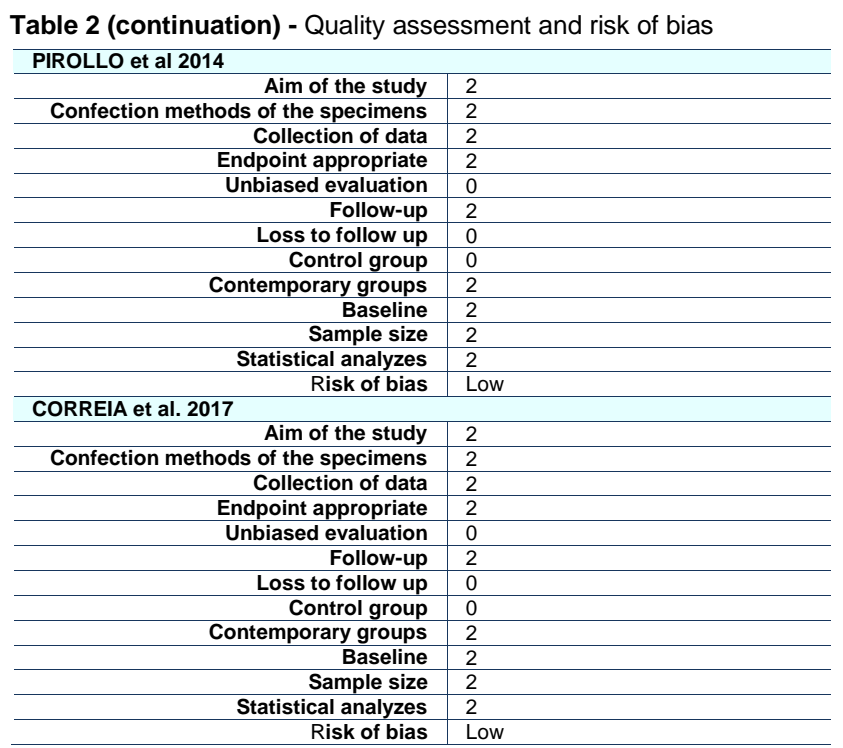

Regarding the bleaching gel and concentrations, carbamide peroxide with concentrations of $10 \%$ to $22 \%$ was used in 5 in vitro studies $2,3,13,16,18$. Hydrogen peroxide with concentrations of $25 \%$ to $35 \%$ was used in 3 in vitro studies $8,14,15$

The bleaching time protocols was varied. The treatment ranging from a single 4 hours session to multiple sessions performed over a period of 28 days, with each session lasting for a maximum duration of 6 hours. The light emitter diode (LED) was used in 2 studies $^{14,15}$.

Seven in vitro studies evaluated color variation using reflectance spectrophotometry ${ }^{2,3,8,13-16,18}$. Among these studies, 3 used $\Delta \mathrm{E}$ as a parameter for quantification of tooth color variation ${ }^{2,3,8}, 1$ study evaluated $\Delta \mathrm{a}^{16}$, and 1 study evaluated $\Delta \mathrm{W}^{15}$.

Of all the in vitro studies, 18 analyzes were performed associating bleaching agents with coloring substances. In 10 analyzes $(55.6 \%)$ the use of this substances during or immediately after the bleaching treatment did not influence the final result.

Coffee was the coloring substance most used and, in the most cases, there was no influence on the final result. Wine was the second substance most used and influenced the final result in $50 \%$ of the analyzes.

Regarding the environmental storage, eight analysis have used artificial saliva to store the specimens and 10 have used distilled water. DISCUSSION

Dentists generally recommend the removal of coloring substances from food and beverages during whitening treatments to avoid the aversive effects on the final whitening result ${ }^{1}$. This systematic review was carried out to obtain a consensus on this topic based on the results of relevant studies. The hypothesis that the coloring substances used during, and / or immediately after, treatment affect the effectiveness of tooth whitening has been partially rejected. Most of in vitro analyzes on this systematic review demonstrate that the coloring substances used during and / or immediately after treatment did not interfere teeth whitening ${ }^{2,3,8,14,15,16,17}$.

This aesthetic procedure can be performed for clinical purposes using high concentrations of hydrogen peroxide or by patients at home, using individualized low concentrations of carbamide peroxide ${ }^{18}$. Two studies analyzed the coffe pigmentation immediately after using carbamide peroxide gel bleaching ${ }^{13,16}$. In the studies by Attia et al. ${ }^{13}$ and Côrtes et al. ${ }^{16}$ the specimen were immersed in coffee during the whitening sessions, and the studies obtained different results, as Côrtes et al. ${ }^{16}$ reported that there was no influence of the solution with pigmentation potential on the final result. This difference cannot be attributed to the concentration of the whitening gel, since concentrations of 10 to $20 \%$ of carbamide peroxide are effective for whitening and statistically similar in terms of whitening treatment $^{16}$. The difference in the result may be related to immersion in artificial saliva for a longer time. Attia et al. ${ }^{13}$ bleached samples were stored in artificial saliva for $5 \mathrm{~min}$, and this time was insufficient to make the enamel resistant to coffee surface stains, while Côrtes et al. ${ }^{16}$ stored the samples in artificial saliva for $2 \mathrm{~h}$ after bleaching, then immerse in coffee solution, and reserved the specimens in artificial saliva again for $17 \mathrm{~h} 45 \mathrm{~min}$ simulating oral conditions.

In this way, saliva acts to replace lost minerals (remineralization) with the dental structure during whitening ${ }^{9,19}$. It can also neutralize the low $\mathrm{pH}$ of the coffee ${ }^{19}$, which justifies the favorable results obtained. A positive result was also found in the clinical study by Rezende et al. $^{9}$, in which it was concluded that, exposure to coffee during tooth whitening performed at home with $16 \%$ carbamide peroxide did not affect tooth sensitivity or the effectiveness of tooth whitening. When analyzing hydrogen peroxide in concentrations of 25 to $35 \%$, it can be noted that the coffee solution also did not interfere with the effectiveness of tooth whitening $8,14,15$.

The results of this review showed unfavorable results obtained when the enamel was exposed to soft drinks with cola and red wine. Cola soda $(\mathrm{pH} 2.60)$ and red wine $(\mathrm{pH}$ 3.60) are highly acidic solutions compared to coffee (pH 5.11). This shows that the low $\mathrm{pH}$ of these solutions may have had an important 
effect on the structure of bleached teeth. In addition to color change, modifications in the micro morphological nature of tooth enamel may be associated with the use of bleaching agents of low or high concentration, including enamel erosion or porosity, greater surface roughness and increased permeability ${ }^{20}$. These effects can be enhanced with soft drinks with cola and red wine [20]. In addition to the low $\mathrm{pH}$, the erosive loss of enamel is greater with the cola, due to the presence of phosphoric acid which has a high erosive power ${ }^{21}$. In addition, the acid nature of the wine associated with ethanol increases the demineralization of the enamel surface, favoring the penetration of these solutions, influencing the general change in the color of the teeth during the whitening treatment ${ }^{2,14,16,21}$.

Toothbrushing and fluoride toothpaste can affect the result of tooth whitening. They can increase the potential for remineralization and prevent the penetration and deposition of the coloring substance during the bleaching treatment ${ }^{9,22}$. In addition, polishing can obtain a smooth enamel surface that makes it difficult to retain coloring substances ${ }^{15}$. However, in the study by De Araujo et al. ${ }^{3}$, even with brushing and fluoride toothpaste during whitening, red wine and cola soda influenced the dental result of whitening. This suggests that when the colorant drink has a very acidic $\mathrm{pH}$, mechanical cleaning with or without fluoride is not able to stop tooth substance retention / penetration.

Several methods have been used to assess tooth color, such as spectrophotometers, colorimeters and techniques for analyzing computer images ${ }^{13}$. In this review, studies in which only reflectance spectrophotometry was used as an evaluation method were eligible due to an accurate and reliable process. According Gehrke et al. $^{23}$, the spectrophotometer used in the study showed $82 \%$ accuracy between two consecutive measurements of the same sample, while the colorimeter represented $70 \%$.

The main limitation of the present study was the articles included are in vitro studies. An in vitro study may not be able to reproduce all conditions in the oral cavity and therefore may not be applicable to actual oral conditions. In addition, the methodologies applied in these studies varied both in the treatment and in the concentration of bleaching and coloring substances. The ideal clinical evidence is always provided by a randomized clinical trial, because the results are applicable to real oral conditions. However, only one study in the literature carried out this methodology ${ }^{9}$; this finding can be explained by the difficulty in conducting randomized clinical studies on whitening treatment. This review highlights the need for more clinical studies to evaluate more accurately the influence of these colorants during whitening treatment, as results may vary under real oral conditions.

CONCLUSION

Coffee does not seem to influence tooth whitening when consumed during tooth whitening sessions or immediately after treatment (up to $24 \mathrm{~h}$ after treatment). However, beverages with to low $\mathrm{pH}$, such as red wine and cola soft drinks may have the potential to alter pigmentation and influence tooth color change.

REFERENCES

1. Briso AL, Fagundes TC, Gallinari MO, Moreira $\mathrm{J}$, Almeida Lcag, Rahal V et al. An In Situ Study of the Influence of Staining Beverages on Color Alteration of Bleached Teeth. Oper Dent. 2016;41;627-33.

2. Correia AMO, Melo BED, Cedraz JSB, Rocha DM, Santos NB, Fragoso LSM. Influence of solutions with pigmentation potential on tooth color after bleaching using $22 \%$ carbamide peroxide. Biosci J. 2017;33(4):1106-12.

3. Araújo LSN, dos Santos PH, Anchieta RB, Catelan A, Briso ALF, Zaze ACSF et al. Mineral loss and color change of enamel after bleaching and staining solutions combination. J Biomed Opt. 2013;18(10):108004

4. Arruda AM, dos Santos $P H$, Sundfeld $R H$, Berger SB, Briso ALF. Effect of 35\% hydrogen peroxide on enamel morphology and interference in de-remineralization process: An in situ study. Oper Dent. 2012;37:518-25.

5. Mondelli LRF, Garrido GTR, Piola RFA, Magalhães AC, Soares BJF, Ishikiriama SK. Do different bleaching protocols affect the enamel microhardness? Eur J Dent. 2015;9:25-30.

6. Polydorou O,S ScheitzaS, M Spraul,K Vach,E Hellwig. The effect of long-term use of tooth bleaching products on the human enamel surface. Odontology. 2018;106:64-72.

7. Klaric E, Rakic M, Sever I, Milat O, Par M, Tarle $Z$. Enamel and dentin microhardness and chemical composition after experimental lightactivated bleaching. Oper Dent. 2015;40:13241.

8. Pirolo R, Mondelli RF, Correr GM, Gonzaga CC, Furuse AY. Effect of coffee and a colabased soft drink on the color stability of bleached bovine incisors considering the time elapsed after bleaching. J Appl Oral Sci. 214;22;534-40.

9. Rezende M, Loguercio AD, Reis A, Kossatz S. Clinical effects of exposure to coffee during athome vital bleaching. Oper Dent. 2013;38: 229-36.

10. Moher D, Liberati A, Tetzlaff J, Altman DG. Preferred reporting items for systematic reviews 
and meta-analyses: the PRISMA statement. Int J Surg. 2010;8:336-41.

11. Slim K, Nini E, Forestier D, Kwiatkowski F, Panis Y, Chipponi J. Methodological index for non-randomized studies (minors): development and validation of a new instrument. ANZ J Surg. 2003;73:712-16.

12. Landis R, Koch GG. The measurement of observer agreement for categorical data. Biometria. 1977;33:159-74.

13. Attia ML, Aguiar FH, Mathias $\mathrm{P}$, Ambrosano GM, Fontes CM, Liporoni PC. The effect of coffee solution on tooth color during home bleaching applications. Am J Dent. 2009;22:175-79.

14. Liporoni PC, Souto CM, Pazinatto RB, Cesar IC, Rego MA, Mathias $P$ et al. Enamel susceptibility to coffee and red wine staining at different intervals elapsed from bleaching: a photoreflectance spectrophotometry analysis. Photomed Laser Surg. 2010;28:105-9.

15. Scaminaci RD, Viano M, Bambi C, Nieri M, Giachetti L. Color stability of bleached teeth over time: an in vitro study. Eur J Esthet Dent. 2010; 5:300-10.

16. Côrtes G, Pini NP, Lima DA, Liporoni PC, Munin E, Ambrosano GM et al. Influence of coffee and red wine on tooth color during and after bleaching. Acta Odontol Scand. 2013;71:1475-80.

17. Azer SS, Hague AL, Johnston WM. Effect of bleaching on tooth discolouration from food colourant in vitro. J Dent. 2010;39:52-6.

18. Rodrigues JL, Rocha PS, Pardim SLS, Machado, ACV, Faria-e-Silva AL, Seraidarian PI. Association between in-office and at-home tooth bleaching: a single blind randomized clinical Trial. Braz Dent J. 2018;29(2):133-39.

19. Setien V, Roshan S, Cala C, Ramirez R. Pigmentation susceptibility of teeth after bleaching with 2 systems: an in vitro study. Quintessence Int. 2009;40:47-52.

20. Carlos N, Pinto A, do Amaral Flb, França FMG, Turssi CP, Basting RT. Influence of Staining Solutions on Color Change and Enamel Surface Properties During At-home and Inoffice Dental Bleaching: An In Situ Study. Oper Dent. 2019;44(6):595-608.

21. Attin $T$, Weiss $K$, Becker $K$, Buchalla W, Wiegand A. Impact of modified acid soft drinks on enamel erosion. Oral Dis. 2005;11:7-12.

22. Oliveira R, Basting RT, Rodrigues JA, Rodrigues Jr AL, Serra MC. Effects of a carbamide peroxide agent and desensitizing dentifrices on enamel microhardness. Am J Dent. 2003;16:42-6.
23. Gehrke P, Riekeberg U, Fackler O, Dhom G. Comparison of in vivo visual, spectrophotometric and colorimetric shade determination of teeth and implant-supported crowns. Int J Comput Dent. 2009;12(3):247-63.

\section{CONFLICTS OF INTERESTS}

The authors declare no conflicts of interests.

\section{CORRESPONDING AUTHOR}

\section{Cleber Davi Del Rei Daltro Rosa}

Dentistry School, UNESP - São Paulo State University

Rua José Bonifacio,1193 - Vila Mendonça

16015-050 Araçatuba SP, Brazil.

Phone: +551- 8992003050

Email: cleberdavi2@hotmail.com
Received 01/02/2021

Accepted 18/07/2021 